\title{
Ultra-processed Foods, Weight Gain, and Co-morbidity Risk
}

\author{
Anthony Crimarco ${ }^{1}\left[\right.$ Matthew J. Landry ${ }^{1}\left[\right.$ Christopher D. Gardner ${ }^{1}([)$
}

Accepted: 3 September 2021 / Published online: 22 October 2021

(c) The Author(s) 2021

\begin{abstract}
Purpose of Review The purpose of this review is to provide an update on the available data regarding the associations of Ultra-processed food (UPF) consumption with food intake and possible underlying mechanisms relating UPF consumption to weight gain and co-morbidities.

Recent Findings In primarily observational studies, UPF consumption is consistently associated with an increased risk for weight gain among adults and children and increased risk for adiposity-related co-morbidities in adults. In a single mechanistic study, consumption of UPFs led to increased energy intake and weight gain relative to whole foods.

Summary UPFs tend to be more energy-dense than nutrient-dense, and UPF consumption is associated with increased adiposity and co-morbidity risk. These data suggest that recommendations to limit UPF consumption may be beneficial to health — though further mechanistic studies are needed.
\end{abstract}

Keywords Ultra-processed foods $\cdot$ Weight gain $\cdot$ NOVA $\cdot$ Weight management $\cdot$ Chronic disease

\section{Introduction}

Food processing includes any variety of operations to modify and alter raw foods from their natural state to make them more suitable for consumption, cooking, or storage [1]. This includes heating, freezing, washing, fermentation, grinding, packaging, and other operations. Since prehistoric times, our ancestors mastered the use of fire for the purpose of heating and cooking foodstuffs to preserve their organoleptic and nutritional properties [2]. During more recent historical events like the Industrial Revolution or the second World War, the focus on food processing began to shift from home cooking to more industrialized processes to emphasize the preservation, safety, and nutritional quality of foods [2].

Food processing has been integral to providing safe, edible, and nutritious foods to the population for centuries. It is useful for increasing the shelf life of foods, optimizing nutrient availability and food quality, as well as to reduce losses and waste $[3,4]$. Since the nineteenth century, a number of

This article is part of the Topical Collection on Etiology of Obesity

Anthony Crimarco and Matthew J. Landry are co-first-authors.

Christopher D. Gardner

cgardner@stanford.edu

1 Stanford Prevention Research Center, School of Medicine, Stanford University, Palo Alto, CA, USA technologies in food processing were introduced, including canning and pasteurization. This was followed by many types of physical, thermal, and chemical processes, such as centrifugation and sterilization of dairy products, or bleaching vegetable oils [5]. The topic of food processing is complex, and the different types of processes bring both benefits and risks. For example, heat processing increases the shelf life and decreases the pathogenic potential of raw milk, but promotes the loss of nutritional value or the production of mutagenic or carcinogenic molecules in others $[2,6]$. Thus, different types of food processing bring both benefits and risks.

Advancements in food processing and changes to our agro-industrial systems have led to the development of numerous food products that contribute to the so-called "Westernized diet." These Westernized food products are usually highly processed and energy-dense, and they contain high amounts of added sugar, saturated fat, and salt, but low amounts of fiber [7]. The concerns about the health effects of industrial processing on diet quality and chronic disease risk has resulted in food classification systems to distinguish between different categories of processed foods [8]. The most popular of those food classification systems is the NOVA (not an acronym) system, which introduced the term "ultra-processed foods" to describe the highest level of food processing [8,9]. Ultra-processed foods (UPFs) tend to be highly palatable, convenient, shelf stable, and affordable, 
and are often marketed and advertised in appealing ways [7, 10-13]. Since the term UPFs was coined, there were 72 articles published on the subject between 2009 and 2016 and another 565 articles from 2017 and 2021 (based on a PubMed search of title words). The increased focus on the health effects of UPFs has resulted in a number of studies assessing the association between UPFs with weight gain and/or co-morbidity risk.

There have also been recent studies that documented an increased consumption of UPFs during the shelter-in-place lockdowns that were implemented to prevent the spread of the novel coronavirus (COVID-19) [14-16]. This was largely attributable to an increase in fast foods and the consumption of low-quality meals or snacks, such as sweets, chocolates, sugar-added beverages, and processed meat. A recent review indicated that only one study showed any improvement in food quality intake (i.e., increased fruit and vegetable consumption) among participants during the shelter-in-place period [16].

Based on the growing interest and potential concerns about the adverse health effects associated with consuming UPFs, the purpose of this review is to examine recent literature (i.e., within the last 5 years) on UPF consumption and its association with weight gain and/or co-morbidity risk. We also discuss the potential mechanisms of how UPFs increase the risk of gaining weight and developing chronic diseases, as well as the limitations of the NOVA classification system.

\section{Defining Ultra-Processed Foods}

In food science and technology, the level of food processing is based on the intensity and amount of operations utilized to enhance shelf life, food safety, food quality, and availability of edible parts of raw materials [17, 18]. There are numerous definitions of food processing from organizations like the International Food Information Council (IFIC) [19] or the International Agency for Research on Cancer-European Prospective Investigation into Cancer (IARC-EPIC) [20]. In general, these classification systems were designed by researchers to study the relationships between industrial products and nutritional intake and/or chronic disease risk [3]. The United States Department of Agriculture (USDA) defines a processed food as "any raw agricultural commodity that has been subject to washing, cleaning, milling, cutting, chopping, heating, pasteurizing, blanching, cooking, canning, freezing, drying, dehydrating, mixing, packaging, or other procedures that alter the food from its natural state" [21].

The NOVA system is one of the most popular food classification systems for categorizing foods and beverages in the public health literature. One of the first systematic reviews on food processing that was published in this journal concluded that NOVA was the most specific, coherent, clear, comprehensive and workable definition [22]. The NOVA criteria involve classifying food products into four groups based on the amount of processed ingredients: (1) unprocessed or minimally processed foods, (2) processed culinary ingredients, (3) processed foods, and (4) ultra-processed foods (UPFs) [9]. See Fig. 1 for the complete definitions of all food categories. The UPF category is described as "formulations mostly of cheap industrial sources of dietary energy and nutrients plus additives, using a series of processes" [9]. Some examples include reconstituted meats, frozen pizzas, and confectionary foods, to name a few. The concept of UPFs was originally coined and developed by a team from the University of São Paulo in a 2009 commentary [8]. The main argument of the commentary was that the extent to which foods are processed, rather than specific nutrients
Fig. 1 Spectrum of processing of foods based on the NOVA classification. The figure provides examples of foods and types of processing methods within each NOVA classification group. Definitions are adapted from Monteiro et al. (2018) [8]
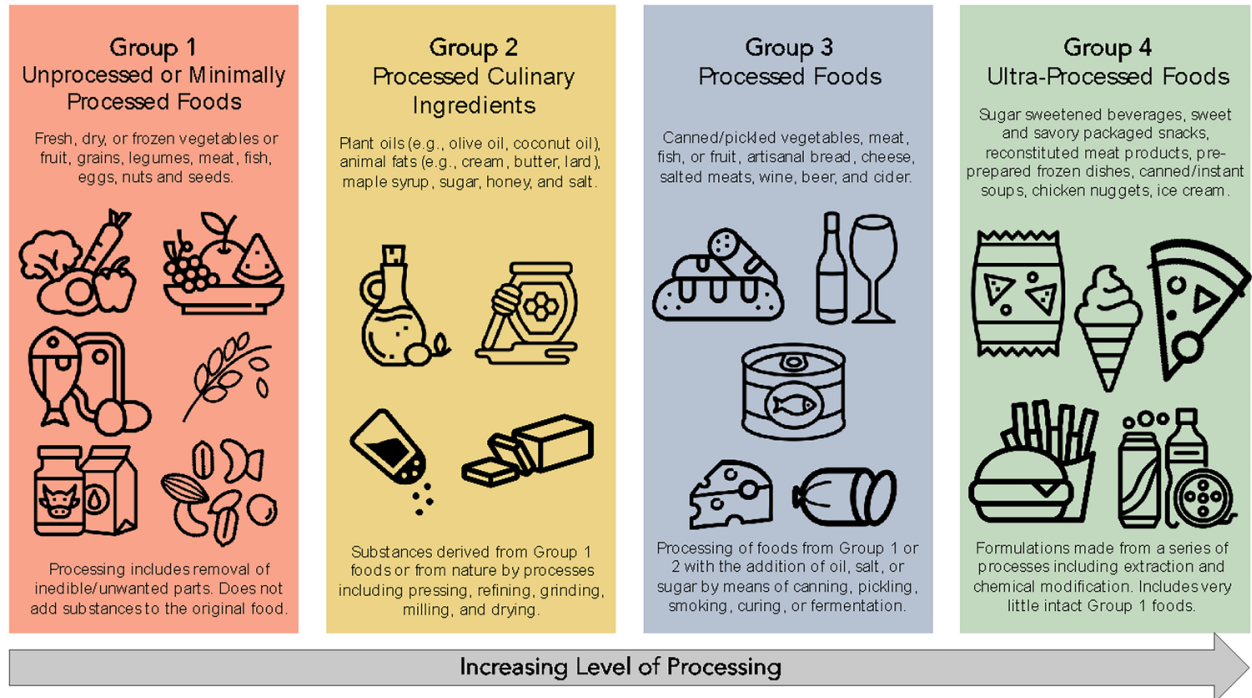
or food items, is the most important factor for determining the relationship between nutrition and chronic diseases. This work has now been formally adopted as a part of the national dietary guidelines in Brazil [23] and has been acknowledged in several leading reports, such as the Food and Agriculture Organization (FAO) of the United Nations [24] or the Pan American Health Organization (PAHO) of the World Health Organization (WHO) [25].

Because the food manufacturing industry is not required to state the processes used in its products on food labels and the information required on food labels is not standardized across countries, it can be difficult for consumers to identify UPFs easily [7, 26]. For example, products like plain steelcut oats, plain corn flakes, and shredded wheat are classified as minimally processed foods, but the same foods are considered processed when they also contain sugar, and ultraprocessed if they also contain flavors or colors [7]. A general rule of thumb is to identify food substances or additives whose primary function is to make the final product more palatable or more appealing (i.e., "cosmetic additives"). This includes items like hydrolyzed proteins, high-fructose corn syrup, and interesterified oils, to name a few.

Because classification systems like NOVA largely rely on categorizing a processed food category based on the content of added sugars, saturated fat, and sodium, it is possible to misclassify some nutrient-rich foods as ultra-processed [27]. For example, in Drewnowski et al.'s analysis of various foods using both the Nutrient Rich Food and NOVA criteria, fortified ready-to-eat cereals, as well as beans and nuts (in the form listed in the FFQ), were classified as ultraprocessed from the NOVA definitions [27]. Additionally, when conducting diet assessments for research purposes (e.g., food frequency questionnaires, 24-h recalls), it is not typical to specify the level of processing involved in reported foods, and thus misclassification may also result here [28]. For example, using the NOVA classification system, commercially baked bread has been classified as ultra-processed, whereas the same bread was considered processed when homemade [29]. Foods that are processed by innovative, non-traditional techniques, such as electric or magnetic fields, may be deemed as minimally processed, despite the use of non-traditional, complex processes [30-32]. Some of the guidelines on UPFs may imply that food processing as a concept has a negative connotation. Sadler et al. [3] note that this could potentially "encourage consumers to seek out unprocessed foods (e.g. raw milk) or process foods at home, without sufficient food safety controls, and such consumer rejection could also hamper sustainable innovations" [3].

More terms and definitions have recently been added to address some of the classification problems within the original NOVA criteria. The Siga classification of processed foods extends the NOVA classification system by combining the original 4 categories of food processing with 5 more specific subgroups [33]. This classification system accounts for added sugar, fat, and salt contents; "at risk" additives; "matrix" effects; ultra-processed ingredients; and the number of markers of ultra-processing (MUPs). Most of the literature to date still utilizes the original NOVA criteria; there have not yet been many studies published utilizing the Siga criteria [33].

\section{Ultra-Processed Food Consumption Levels}

UPFs are expanding in food systems across the globe. A number of articles have been published on the contribution of UPF consumption to daily total energy intake in different countries. Table 1 shows selected recent articles on the subject. In general, the majority of calories consumed in high-income countries are from ultra-processed foods and beverages. For example, in Canada, the UK, and the USA, UPF products were estimated to contribute $45.0 \%, 50.4 \%$, and $57.9 \%$ of total energy intake, respectively [34-36]. For other countries like Brazil, UPFs contributed $22.7 \%$ of total energy intake. For other countries like Brazil, UPFs contributed $22.7 \%$ of total energy intake. But it should be noted that older studies (not shown in Table 1) have indicated that UPFs contributed anywhere from 21.5 to $51.2 \%$ of total energy intake, depending on the sample [37, 38]. Most samples included children and adults, while two focused only on children [39, 40]. Monteiro et al. (2018) assessed household availability of NOVA food groups in 19 European countries and analyzed the association between availability of UPF and prevalence of obesity [35]. A strength of the study was the use of standardized data and the use of population-based, actual (non-modeled) estimates of the prevalence of obesity. After adjusting for multiple confounding factors, each percentage point increase in the household availability of UPF resulted in an increase of 0.25 percentage points in obesity prevalence.

UPF consumption levels also appear to coincide with obesity rates in some of the countries (Fig. 2) [41]. For example, the USA and UK had the highest rates of UPF consumption and obesity. However, for other countries there are inconsistencies. Portugal had a relatively low UPF consumption rate (10.2\%), but still has an obesity rate of $20.8 \%$, which is comparable to other European countries [41]. Although UPFs are a significant source of energy intake, they are just one group of foods among all the possible sources of energy intake in the diet, and other factors also contribute to obesity rates.

\section{Sociodemographic Characteristics}

Prior studies have consistently shown that UPF consumption differs among strata of sociodemographic characteristics [34, 42-49]. Differences in consumption vary by gender, 
Table 1 Select recent articles on ultra-processed food consumption levels from various countries

\begin{tabular}{|c|c|c|c|}
\hline Articles & Country & Sample & Key findings \\
\hline Machado et al. [102] & Australia & $\begin{array}{l}\text { 12,153 individuals from the National Nutrition } \\
\text { and Physical Activity Survey (2011-2012) } \\
\text { ages } 2 \text { years and above }\end{array}$ & $\begin{array}{l}\text { Consumption of ultra-processed foods consisted } \\
\text { of } 42.0 \% \text { of total energy intake }\end{array}$ \\
\hline Harris et al. [103] & Barbados & $\begin{array}{l}\text { Nationally representative population-based } \\
\text { sample of } 364 \text { adult Barbadians }\end{array}$ & $\begin{array}{l}\text { Consumption of ultra-processed foods consisted } \\
\text { of } 40.5 \% \text { of total energy intake }\end{array}$ \\
\hline Simões et al. [45] & Brazil & $\begin{array}{l}\text { 14,378 adults ages between } 35 \text { and } 74 \text { years } \\
\text { sampled at multicenter cohort from } 6 \text { public } \\
\text { universities }\end{array}$ & $\begin{array}{l}\text { Consumption of ultra-processed foods consisted } \\
\text { of } 22.7 \% \text { of total energy intake }\end{array}$ \\
\hline Nardocci et al. [34] & Canada & $\begin{array}{l}9363 \text { adults ages } 18 \text { years or more from the } \\
2004 \text { Canadian Community Health Survey }\end{array}$ & $\begin{array}{l}\text { Consumption of ultra-processed foods consisted } \\
\text { of } 45.0 \% \text { of total energy intake }\end{array}$ \\
\hline Cediel et al. [49] & Chile & 4920 individuals ages 2 years and above & $\begin{array}{l}\text { Consumption of ultra-processed foods consisted } \\
\text { of } 28.6 \% \text { of total energy intake }\end{array}$ \\
\hline Cornwell et al. [39] & Colombia & 223 children ages $5-12$ years & $\begin{array}{l}\text { Consumption of ultra-processed foods consisted } \\
\text { of } 34.4 \% \text { of total energy intake }\end{array}$ \\
\hline Monteiro et al. [35] & $\begin{array}{l}\text { Multiple European } \\
\text { countries }\end{array}$ & $\begin{array}{l}\text { Households from the Living Costs and Food } \\
\text { Survey (LCFS) or the Data Food Networking } \\
\text { (DAFNE) }\end{array}$ & $\begin{array}{l}\text { Consumption of ultra-processed foods consisted } \\
\text { of } 26.4 \% \text { of total energy intake. The range of } \\
\text { calories consumed from ultra-processed foods } \\
\text { were } 10.2 \% \text { of total energy intake in Portugal } \\
\text { to } 50.4 \% \text { of total energy intake from the UK }\end{array}$ \\
\hline Setyowati et al. [104] & Indonesia & $\begin{array}{l}\text { Children and adults ( } n=145,360) \text { grouped into } \\
\text { the following age groups: } 0-4,5-12,13-18 \text {, } \\
19-55 \text {, and }>55 \text { years }\end{array}$ & $\begin{array}{l}\text { Consumption of ultra-processed foods consisted } \\
\text { of } 15.7 \% \text { of total energy intake }\end{array}$ \\
\hline $\begin{array}{l}\text { Marrón-Ponce et al. } \\
\text { [44] }\end{array}$ & Mexico & $\begin{array}{l}10,087 \text { individuals from the } 2012 \text { Mexican } \\
\text { National Health and Nutrition Survey }\end{array}$ & $\begin{array}{l}\text { Consumption of ultra-processed foods consisted } \\
\text { of } 29.8 \% \text { of total energy intake }\end{array}$ \\
\hline Fangupo et al. [40] & New Zealand & $\begin{array}{l}669 \text { children ages } 1-5 \text { years born in Dunedin, } \\
\text { New Zealand }\end{array}$ & $\begin{array}{l}\text { Consumption of ultra-processed foods } \\
\text { consisted of } 45.0 \%, 42.0 \% \text {, and } 51.0 \% \text { of } \\
\text { energy intake to the diets of children at } 12,24 \text {, } \\
\text { and } 60 \text { months of age, respectively }\end{array}$ \\
\hline Steele et al. [36] & USA & 9317 individuals ages 1 year and above & $\begin{array}{l}\text { Consumption of ultra-processed foods consisted } \\
\text { of } 57.9 \% \text { of total energy intake }\end{array}$ \\
\hline
\end{tabular}

age, ethnicity, education, children within the household, nativity, and time for meal preparation depending on the sample (Table 2). The literature has also suggested that an individual's or a household's socioeconomic status may be an important factor associated with the consumption of greater ultra-processed foods; however, these associations vary by a country's income level. Globally, differences between countries can be attributable to differences
Fig. 2 Comparison of select countries totally energy intake from UPFs and obesity rates. Colombia and New Zealand were not included in the graphs, since those studies were based on children only. The obesity rates are based on 2016 data by the World Health Organization (WHO) [41]. Therefore, the rates are not necessarily equivalent to the dietary data from the selected articles

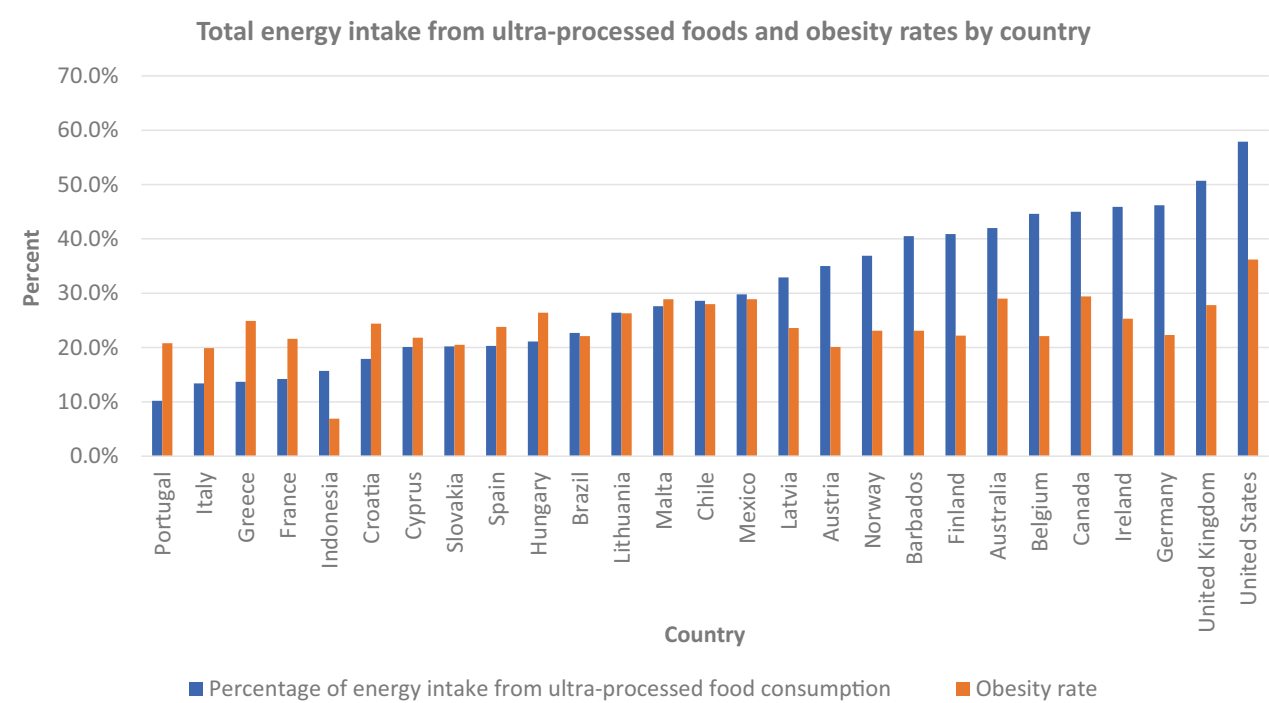


in food price, affordability, and accessibility [50]. Within the USA, higher consumption of UPF is associated with lower income and education, and studies have documented that UPF account for a larger proportion of grocery spending within households participating in Supplemental Nutrition Assistance Program compared to households not participating [51-53]. Similar results have been found within other high-income countries [42, 47, 54]. The opposite is observed within middle- and low-income countries as those of higher socioeconomic status, those living within urban centers, and those with greater educational attainment are associated with greater UPF intakes [43, 44, 49]. In middle- and low-income countries, there is likely to be more subsistence farming, where families eat more of the food they grow or raise; these foods would be more likely to be whole foods. Those with higher incomes within these countries deviate from traditional dietary patterns as they can afford the purchase of more Westernized foods that are more likely to be processed or ultra-processed.

\section{Associations of Ultra-Processed Foods with Weight Gain and Disease Risk in Adults}

Although the majority of studies on the health effects of UPFs are observational in nature, there is growing evidence that they contribute to weight gain and increase the risk for some chronic diseases [55]. A meta-analysis of 43 studies (21 cross-sectional, 19 prospective cohort, 2 case-control, and 1 conducted both as a cross-sectional and prospective analysis) indicated that the consumption of UPFs was associated with an increased risk of overweight (odds ratio: 1.36; 95\% confidence interval [CI], 1.23-1.51; $P<0.001)$, obesity (odds ratio: $1.51 ; 95 \% \mathrm{CI}, 1.34-1.70 ; P<0.001$ ), abdominal

Table 2 Select recent studies examining sociodemographic factors associated with greater consumption of ultra-processed foods

\begin{tabular}{|c|c|c|}
\hline Article & Country & Sociodemographic Factors Associated with Greater Consumption of UPF \\
\hline Calixto Andrade et al. [105] & France & $\begin{array}{l}\text { - Younger age } \\
\text { - Urban }\end{array}$ \\
\hline Djupegot et al. [42] & Norway & $\begin{array}{l}\text { - Men } \\
\text { - Native Norwegian } \\
\text { - Lower educational attainment } \\
\text { - } \geq 3 \text { children within the home } \\
\text { - Younger age }\end{array}$ \\
\hline Nardocci et al. [42] & Canada & $\begin{array}{l}\text { - Men } \\
\text { - Younger age } \\
\text { - Lower educational attainment } \\
\text { - Smokers } \\
\text { - Physically inactive } \\
\text { - Canadian-born individuals }\end{array}$ \\
\hline Khandpur et al. [43] & Columbia & $\begin{array}{l}\text { - Younger age } \\
\text { - Higher socioeconomic status } \\
\text { - Area of residence/geographic region } \\
\text { - Urban }\end{array}$ \\
\hline Marrón-Ponce et al. [44] & Mexico & $\begin{array}{l}\text { - Younger age } \\
\text { - Urban } \\
\text { - Higher socioeconomic status } \\
\text { - Lower educational attainment } \\
\text { - Geographical region }\end{array}$ \\
\hline Machado et al. [48] & Australia & $\begin{array}{l}\text { - Younger } \\
\text { - Australian or English country } \\
\text { - Physically inactive } \\
\text { - Smoker } \\
\text { - Lower educational attainment } \\
\text { - Urban }\end{array}$ \\
\hline Cediel et al. [49] & Chile & $\begin{array}{l}\text { - Younger } \\
\text { - Urban } \\
\text { - Geographic region } \\
\text { - Higher income }\end{array}$ \\
\hline Baraldi et al. [53] & USA & $\begin{array}{l}\text { - Non-Hispanic Whites and Non-Hispanic Blacks (compared to other } \\
\text { race/ethnicity groups) } \\
\text { - Higher educational attainment } \\
\text { - Younger age } \\
\text { - Lower income level }\end{array}$ \\
\hline
\end{tabular}


obesity (odds ratio: 1.49 ; $95 \% \mathrm{CI}, 1.34-1.66 ; P<0.0001$ ), all-cause mortality (hazard ratio: 1.28 ; 95\% CI, 1.11-1.48; $P=0.001$ ), and metabolic syndrome (odds ratio: $1.81 ; 95 \%$ CI, $1.12-2.93 ; P=0.015)$ in adults [56]. A recent systematic review of 23 studies (10 cross-sectional and 13 prospective cohort) also found an association between UPF consumption and an increased relative risk for overweight/ obesity $(+39 \%)$, high waist circumference $(+39 \%)$, low HDL-cholesterol levels (+102\%), and metabolic syndrome $(+79 \%)$ [57]. An analysis on a subsample of adult men and women from the PREDIMED-Plus cohort with obesity and metabolic syndrome indicated that higher UPF consumption was associated with greater accumulation of visceral fat, android-to-gynoid fat ratio, and total body fat [58].

A number of other recent reviews that assessed UPF consumption on weight gain, or increased health risk, have reported similar findings (Table 3). The majority of these studies are cross-sectional; therefore, while increased UPF consumption tends to be evident in people with greater adiposity and co-morbidities, the nature of the study design does not indicate any direction of causality. It is worth noting that obesity is a multifactorial disease with many related lifestyle contributors. Given the majority of research on UPFs is observational in nature, residual confounding is possible.

Some prospective cohort studies have also reported that UPFs are positively associated with multiple indicators of adiposity (i.e., BMI, waist circumference, and body fat percent) $[59,60]$. A retrospective cohort study indicated that diets rich in UPFs were associated with a 79\% increased risk for obesity (HR 1.79; 95\% CI 1.06-3.03) and a 30\% increased risk for abdominal obesity (HR 1.30; 95\% CI 1.14-1.48 [59]. Additionally, higher consumption of UPFs increased the risk of a gain in BMI, waist circumference, and body fat of 5\% or more during the follow-up period (median of 5.6 years) [59]. A cohort study with civil servants in Brazil indicated that UPF consumption was associated with an increased relative risk of $27 \%$ (95\% CI: $1.07-1.50$ ) weight gain and 33\% increased relative risk (95\% CI: 1.12-1.58) for waist-circumference gain [60]. Fazzino et al. [61] conducted a prospective study among 82 individuals without obesity and found that an increased consumption of UPFs in a buffet meal were associated with greater weight gain over the next 12 months. These findings from cohort studies build on the cross-sectional studies by providing evidence of direction of causality for UPF consumption and weight gain.

In adults, results that are primarily from observational studies generally report that consumption of UPFs is associated with an increased risk of hypertension [62], cardiovascular disease [63], type 2 diabetes [64], metabolic syndrome [65], higher risk of overall cancer [66], and all-cause mortality [67]. Many of these studies adjusted for BMI in the main analyses and/or included sensitivity analyses to adjust for BMI, weight gain, physical activity levels, or a family history of the specific health condition, suggesting that high UPF diets increase one's risk for co-morbidities independent of body weight. In most of these studies, the participants with the highest UPF consumption also consumed diets of lower overall quality. Participants that consumed the most UPFs had higher intakes of sugar, saturated fats, and salt, but lower and/or inadequate intake of fiber and micronutrients compared to those that had consumed fewer UPF products. Therefore, it is plausible that the consumption of UPFs are associated with many of today's leading chronic diseases, since poor diet quality is associated with all of the mentioned health conditions $[68,69]$. However, there are also a number of possible biological mechanisms unique to UPF consumption, in addition to poor diet quality, that potentially explain some of their effects on increased weight gain and/or chronic disease risk, as discussed further below.

\section{Ultra-Processed Foods and Health Outcomes in Children and Adolescents}

While there is extensive evidence from several systematic reviews and meta-analyses [56, 57, 70-72] linking UPFs to health outcomes in adults, research is more limited in pediatric populations. In 2017-2018, UPFs contributed greater than two-thirds of energy intake among US children and adolescents, a 5.6\% increase over the prior 20 years [73]. Additionally, research has found that frequent consumption of UPFs was associated with food addition within overweight children [74]. Together, poor diet quality and excessive caloric intake can contribute to the development of overweight and obesity among children.

Within several prospective studies, higher consumption of UPFs during childhood was associated with more rapid increase in BMI, fat mass index, weight, and waist circumference in adolescence and early adulthood [75-77]. A 2018 systematic review reported that consumption of ultra-processed foods during childhood and adolescence was positively associated with adiposity [80]. Contrarily, several studies have found no association between consumption of ultra-processed foods and weight status or adiposity [78, 79]. Research suggests that null findings may be attributable to factors associated with the etiology of obesity, such as physical activity, genetics, and family lifestyle, which were not assessed within the studies [78, 79]. Given these findings, reducing ultra-processed food consumption among children may reduce the prevalence of overweight and obesity among children; however, a clinical trial within a child population is needed.

In addition to weight and adiposity outcomes, several studies have found a positive association between greater UPF consumption and blood lipids. A Brazilian cohort found that children with the highest consumption of UPFs 


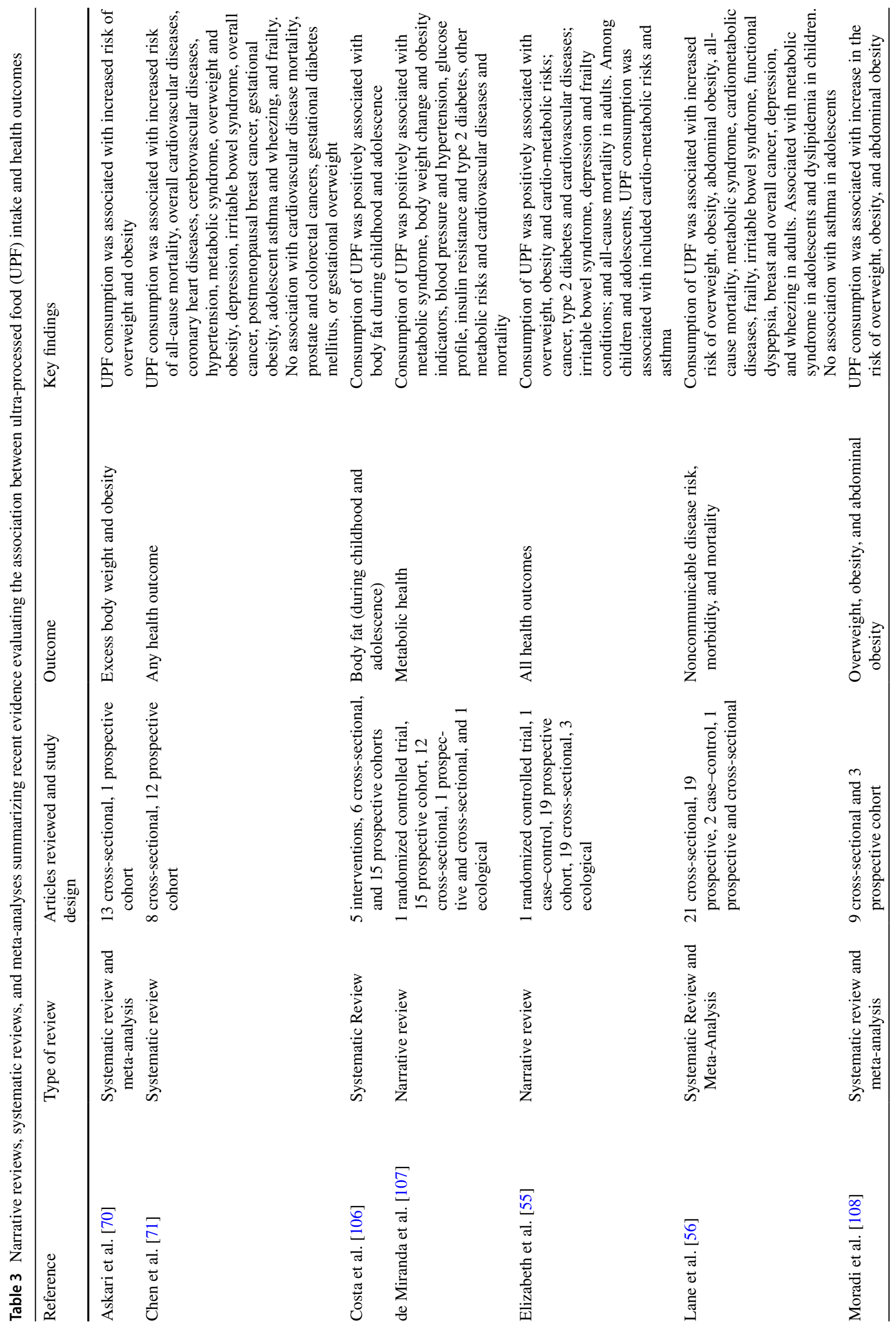




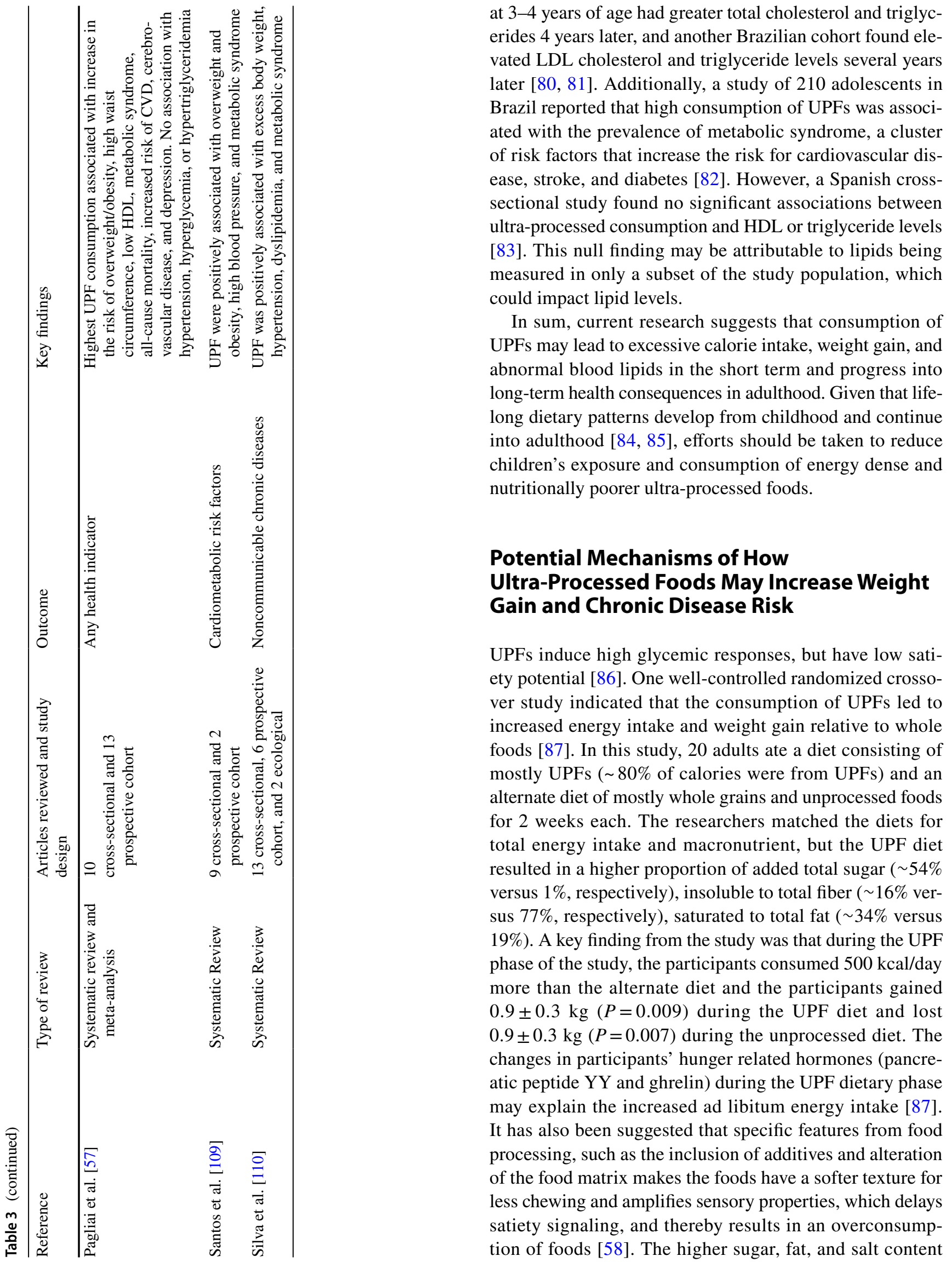


in UPFs makes them more hyperpalatable, which in turn could result in a healthy, nutrient-dense diet being displaced with empty calories and a lower-quality diet that results in weight gain [88].

UPFs also have been reported to contribute to a gut environment that selects microbes that are associated with inflammatory disease [89]. The modification of the food matrix often changes the fiber and fat content of the foods, which influences the microbiota composition and bacteriahost interactions [88]. Minimally processed or natural foods have intact fibrous cell walls that provide a substrate for fiber-degrading bacteria in the colon and ensure a slow release of nutrients along the digestive tract [90]. However, the nutrients in UPFs are largely acellular, which instead results in an environment that promotes inflammatory gut microbiota that are associated with various cardiometabolic conditions [89]. Thus, not only are UPF diets usually low in dietary fiber, but even the way fiber is altered from food processing impacts its effectiveness on promoting a beneficial gut microbiome environment. As reported in an animal model study, the consumption of a high-fiber diet in pigs based on processed, extruded grains reduced bacterial diversity compared to a diet based on unprocessed whole grains [91]. A review of 7 trials indicated that higher UPF diets were the most commonly associated with a reduced abundance of microbes that are linked with beneficial health outcomes and an increased abundance of microbes linked with adverse health outcomes [92].

Another mechanism by which UPF consumption might impact biology or metabolism could involve the endocrinedisrupting chemicals, such as bisphenol A (BPA), often found in the elaborate packaging materials used for UPF products [88]. While the complete mechanisms of BPA remain unknown, there is some evidence that BPA promotes insulin resistance, oxidative stress, inflammation, and adipogenesis, which in turn increases our risk for major CVD conditions, including diabetes, overall and abdominal obesity, and hypertension [93].

Gibney (2019 and 2020) argues that any adverse effects observed from UPFs are due to nutritional factors, rather than the degree to which foods are processed [29, 94]. Findings from the SWAP-MEAT crossover intervention study conducted by our lab group indicated that participants had improvements in several cardiovascular disease risk factors during 8 weeks of consuming alternative plant-based meat products relative to organic animal meats [95]. This was due to the simultaneous decrease in saturated fatty acids and increase in dietary fiber that the plant-based meats provided. It is not clear if the level of food processing increases our risk for weight gain and other chronic diseases independently from the nutritional composition of the foods themselves, since most UPFs by default are dense in energy and poor in nutritional quality [96].
However, in our SWAP-MEAT study, there was a small but statistically significant decrease in weight on the plantbased meat phase vs. animal meat phase. However, our study was designed to focus on a single substitution of plant-based meat for animal meat. In a cohort study where the overall level of UPF consumption was examined, across all food types, the investigators reported that after controlling for several components of nutritional quality, UPFs were associated with a higher risk of cardiovascular disease [63]. Similarly, another study found an increased association between the consumption of ultra-processed foods and type 2 diabetes among individuals from the NutriNet-Santé cohort after controlling for diet quality and energy intake [64].

\section{Policies to Reduce Ultra-Processed Food Consumption}

Acknowledging the negative associations between health and UPF, a number of countries have begun implementing polices in an effort to reduce UPF consumption, including taxes on sugar sweetened beverages or snacks, front-ofpackage (FOP) warning labels, setting limits on sodium and trans-fat content in food products, regulations to reduce or ban the marketing of UPFs, and restricting access and promotion of UPFs in schools [97]. Mexico was one of the first countries to rigorously evaluate its tax policy on sweetened beverages and found that purchases of taxed beverages fell by $6 \%$ and the reductions from pre-tax trends were highest among lower socioeconomic status household [98]. While taxes on UPF foods are effective for reducing the sales of such products, a particular gap in fiscal policy is the absence of subsidies or incentives that promote the purchase of healthier foods [97]. There is evidence that food taxes on unhealthy foods combined with subsidies to purchase healthier foods improves the population's diet quality and health outcomes $[99,100]$. However, implementing more forceful policies remains a challenge, since the food industry and other stakeholders are resistant to reducing UPF consumption or are making efforts to undermine public actions to improve health $[97,101]$.

\section{Conclusions}

Defining the extent of food processing that may be associated with negative health outcomes remains a challenge for the field. Various types of processing remain an integral aspect of providing a safe food system. While the NOVA classification remains the most frequently used method of categorizing foods by level of processing, emerging classification systems seek to build on the limitations of the NOVA 
classification to provide a more accurate assessment of processing. Epidemiological research suggests that UPF consumption is pervasive and contributes a substantial amount of daily total energy intake in individuals around the world. There has been an observed ecological trend that countries with higher UPF consumption generally have a higher obesity prevalence. However, this trend is not observed in all countries, and differences may be attributable to sociodemographic characteristics or other related factors.

Despite the growing literature documenting the potential increase in weight gain and adverse health outcomes in children, adolescents, and adults from the consumption of UPFs, there has only been one randomized clinical trial specifically assessing the effects of UPF consumption [87]. Therefore, most of what is known about UPFs is based on observational cohort studies, limiting conclusions to associations rather than causation. Several plausible mechanisms including increased energy intake, changes to the gut microbiome, alterations in the gut-brain satiety signaling, and hormonal effects have been proposed as plausible explanations of the observed associations between UPF and both weight gain and risk for chronic disease development. Further research to examine the causal effect of consuming UPFs on weight gain and adverse health outcomes is warranted. Given that UPFs tend to be more energy-dense than nutrient-dense, cautionary recommendations to limit UPF consumption would be unlikely to lead to any additional risk or harm, and would more plausibly lead to a nutritional benefit. Therefore, while awaiting further research, recommendations to limit or restrict UPF consumption would likely lead to more benefit than harm.

Funding This work was supported by a training grant from the NIH National Heart, Lung, and Blood Institute (T32 HL007034) and by the Stanford Diabetes Research Center (NIH P30DK116074).

Availability of Data and Materials Not applicable.

\section{Compliance with Ethical Standards}

Conflict of Interest Gardner received a gift funding from Beyond Meat which was used to conduct a research study.

Human and Animal Rights and Informed Consent. This article does not contain any studies with human or animal subjects performed by any of the authors.

Open Access This article is licensed under a Creative Commons Attribution 4.0 International License, which permits use, sharing, adaptation, distribution and reproduction in any medium or format, as long as you give appropriate credit to the original author(s) and the source, provide a link to the Creative Commons licence, and indicate if changes were made. The images or other third party material in this article are included in the article's Creative Commons licence, unless indicated otherwise in a credit line to the material. If material is not included in the article's Creative Commons licence and your intended use is not permitted by statutory regulation or exceeds the permitted use, you will need to obtain permission directly from the copyright holder. To view a copy of this licence, visit http://creativecommons.org/licenses/by/4.0/.

\section{References}

1. Floros JD, Newsome R, Fisher W, Barbosa-Cánovas GV, Chen $\mathrm{H}$, Dunne $\mathrm{CP}$, et al. Feeding the world today and tomorrow: the importance of food science and technology: an IFT scientific review. Comprehensive Reviews in Food Science and Food Safety. 2010;9(5):572-99.

2. van Boekel M, Fogliano V, Pellegrini N, Stanton C, Scholz G, Lalljie $S$, et al. A review on the beneficial aspects of food processing. Mol Nutr Food Res. 2010;54(9):1215-47.

3. Sadler CR, Grassby T, Hart K, Raats M, Sokolović M, Timotijevic L. Processed food classification: conceptualisation and challenges. Trends in Food Science \& Technology. 2021.

4. Augustin MA, Riley M, Stockmann R, Bennett L, Kahl A, Lockett $\mathrm{T}$, et al. Role of food processing in food and nutrition security. Trends Food Sci Technol. 2016;56:115-25.

5. Miclotte L, Van de Wiele T. Food processing, gut microbiota and the globesity problem. Crit Rev Food Sci Nutr. 2020;60(11):1769-82.

6. Costard S, Espejo L, Groenendaal H, Zagmutt FJ. Outbreakrelated disease burden associated with consumption of unpasteurized cow's milk and cheese, United States, 2009-2014. Emerg Infect Dis. 2017;23(6):957.

7. Monteiro CA, Cannon G, Levy RB, Moubarac J-C, Louzada ML, Rauber F, et al. Ultra-processed foods: what they are and how to identify them. Public Health Nutr. 2019;22(5):936-41.

8. Monteiro CA. Nutrition and health. The issue is not food, nor nutrients, so much as processing. Public health nutrition. 2009;12(5):729-31.

9. Monteiro CA, Cannon G, Moubarac J-C, Levy RB, Louzada MLC, Jaime PC. The UN Decade of Nutrition, the NOVA food classification and the trouble with ultra-processing. Public Health Nutr. 2018;21(1):5-17.

10. Mais L, Horta P, Martins A, Claro R. Ultra-processed food and beverage advertising on Brazilian television by International Network for Food and Obesity/Non-Communicable Diseases Research, Monitoring and Action Support benchmark. Public Health Nutr. 2020;23(15):2657-62.

11. Fagerberg P, Langlet B, Oravsky A, Sandborg J, Löf M, Ioakimidis I. Ultra-processed food advertisements dominate the food advertising landscape in two Stockholm areas with low vs high socioeconomic status. Is it time for regulatory action? BMC Public Health. 2019;19(1):1-10.

12. Horta PM, Rodrigues FT, Dos Santos LC. Ultra-processed food product brands on Facebook pages: highly accessed by Brazilians through their marketing techniques. Public Health Nutr. 2018;21(8):1515-9.

13. Turner S, Jones C. The Milkybar'Kid': Nestlé, childhood obesity and the regulation of advertising of high sugar and fat ultraprocessed products. Br Dent J. 2018;225(8):771-6.

14. Ruíz-Roso MB, de Carvalho PP, Matilla-Escalante DC, Brun P, Ulloa N, Acevedo-Correa D, et al. Changes of physical activity and ultra-processed food consumption in adolescents from different countries during Covid-19 pandemic: An observational study. Nutrients. 2020;12(8):2289.

15. Bonaccio M, Costanzo S, Ruggiero E, Persichillo M, Esposito $\mathrm{S}$, Olivieri $\mathrm{M}$, et al. Changes in ultra-processed food 
consumption during the first Italian lockdown following the COVID-19 pandemic and major correlates: results from two population-based cohorts. Public health nutrition. 2021:1-11.

16. Alamri ES. Effects of COVID-19 home confinement on eating behavior: a review. J Public Health Res. 2021.

17. Botelho R, Araújo W, Pineli L. Food formulation and not processing level: conceptual divergences between public health and food science and technology sectors. Crit Rev Food Sci Nutr. 2018;58(4):639-50.

18. Jones JM. Food processing: criteria for dietary guidance and public health? Proc Nutr Soc. 2019;78(1):4-18.

19. Eicher-Miller HA, Fulgoni VL III, Keast DR. Contributions of processed foods to dietary intake in the US from 20032008: a report of the Food and Nutrition Science Solutions Joint Task Force of the Academy of Nutrition and Dietetics, American Society for Nutrition, Institute of Food Technologists, and International Food Information Council. J Nutr. 2012;142(11):2065S-S2072.

20. Chajès V, Biessy C, Byrnes G, Deharveng G, Saadatian-Elahi M, Jenab M, et al. Ecological-level associations between highly processed food intakes and plasma phospholipid elaidic acid concentrations: results from a cross-sectional study within the European prospective investigation into cancer and nutrition (EPIC). Nutr Cancer. 2011;63(8):1235-50.

21. Jones JM, Clemens RA. Processed and ultraprocessed foods defined-an Alice in Wonderland question. Cereal Foods World. 2017;62:120.

22. Moubarac J-C, Parra DC, Cannon G, Monteiro CA. Food classification systems based on food processing: significance and implications for policies and actions: a systematic literature review and assessment. Curr Obes Rep. 2014;3(2):256-72.

23. Monteiro CA, Cannon G, Moubarac J-C, Martins APB, Martins CA, Garzillo J, et al. Dietary guidelines to nourish humanity and the planet in the twenty-first century. A blueprint from Brazil. Public health nutrition. 2015;18(13):2311-22.

24. Food Agriculture Organization of the United Nations. Guidelines on the collection of information on food processing through food consumption surveys. FAO Rome; 2015.

25. Moubarac J. Ultra-processed food and drink products in Latin America: trends, impact on obesity, policy implications. Pan American Health Organization World Health Organization: Washington, DC, USA. 2015:1-58.

26. Messer KD, Costanigro M, Kaiser HM. Labeling food processes: the good, the bad and the ugly. Appl Econ Perspect Policy. 2017;39(3):407-27.

27. Drewnowski A, Gupta S, Darmon N. An overlap between "ultraprocessed" foods and the preexisting Nutrient Rich Foods Index? Nutr Today. 2020;55(2):75-81.

28. Ostfeld RJ, Allen KE. Ultra-processed foods and cardiovascular disease: where do we go from here? : American College of Cardiology Foundation Washington DC; 2021

29. Gibney MJ. Ultra-processed foods: definitions and policy issues. Current developments in nutrition. 2019;3(2):nzy077.

30. Heinrich V, Zunabovic M, Varzakas T, Bergmair J, Kneifel W. Pulsed light treatment of different food types with a special focus on meat: a critical review. Crit Rev Food Sci Nutr. 2016;56(4):591-613.

31. Pérez-Andrés JM, Charoux CmM, Cullen P, Tiwari BK. Chemical modifications of lipids and proteins by nonthermal food processing technologies. J Agric Food Chem. 2018;66(20):5041-54.

32. Misra N, Koubaa M, Roohinejad S, Juliano P, Alpas H, Inácio RS, et al. Landmarks in the historical development of twenty first century food processing technologies. Food Res Int. 2017;97:318-39.

33. Davidou S, Christodoulou A, Fardet A, Frank K. The holisticoreductionist Siga classification according to the degree of food processing: an evaluation of ultra-processed foods in French supermarkets. Food Funct. 2020;11(3):2026-39.

34. Nardocci M, Leclerc B-S, Louzada M-L, Monteiro CA, Batal $\mathrm{M}$, Moubarac J-C. Consumption of ultra-processed foods and obesity in Canada. Can J Public Health. 2019;110(1):4-14.

35. Monteiro CA, Moubarac J-C, Levy RB, Canella DS, da Costa Louzada ML, Cannon G. Household availability of ultraprocessed foods and obesity in nineteen European countries. Public Health Nutr. 2018;21(1):18-26.

36. Steele EM, Baraldi LG, da Costa Louzada ML, Moubarac J-C, Mozaffarian D, Monteiro CA. Ultra-processed foods and added sugars in the US diet: evidence from a nationally representative cross-sectional study. BMJ open. 2016;6(3).

37. Bielemann RM, Motta JVS, Minten GC, Horta BL, Gigante DP. Consumption of ultra-processed foods and their impact on the diet of young adults. Rev Saude Publica. 2015;49:28.

38. Louzada MLdC, Martins APB, Canella DS, Baraldi LG, Levy $\mathrm{RB}$, Claro RM, et al. Ultra-processed foods and the nutritional dietary profile in Brazil. Revista de Saúde Pública. 2015;49.

39. Cornwell B, Villamor E, Mora-Plazas M, Marin C, Monteiro CA, Baylin A. Processed and ultra-processed foods are associated with lower-quality nutrient profiles in children from Colombia. Public Health Nutr. 2018;21(1):142-7.

40. Fangupo LJ, Haszard JJ, Taylor BJ, Gray AR, Lawrence JA, Taylor RW. Ultra-processed food intake and associations with demographic factors in young New Zealand children. J Acad Nutr Diet. 2021;121(2):305-13.

41. ProCon.org: Global Obesity Levels. https://obesity.procon.org/ global-obesity-levels/ (2020). Accessed July 72021.

42. Djupegot IL, Nenseth CB, Bere E, Bjørnarå HBT, Helland SH, $\emptyset$ verby NC, et al. The association between time scarcity, sociodemographic correlates and consumption of ultra-processed foods among parents in Norway: a cross-sectional study. BMC Public Health. 2017;17(1):1-8.

43. Khandpur N, Cediel G, Obando DA, Jaime PC, Parra DC. Sociodemographic factors associated with the consumption of ultraprocessed foods in Colombia. Rev Saude Publica. 2020;54:19.

44. Marrón-Ponce JA, Sánchez-Pimienta TG, da Costa Louzada ML, Batis C. Energy contribution of NOVA food groups and sociodemographic determinants of ultra-processed food consumption in the Mexican population. Public Health Nutr. 2018;21(1):87-93.

45. Simões BdS, Barreto SM, Molina MdCB, Luft VC, Duncan BB, Schmidt MI, et al. Consumption of ultra-processed foods and socioeconomic position: a cross-sectional analysis of the Brazilian Longitudinal Study of Adult Health. Cadernos de saude publica. 2018;34:e0019717.

46. Marrón-Ponce JA, Tolentino-Mayo L, Hernández-F M, Batis C. Trends in ultra-processed food purchases from 1984 to 2016 in Mexican households. Nutrients. 2019;11(1):45.

47. Moubarac J-C, Batal M, Louzada M, Steele EM, Monteiro C. Consumption of ultra-processed foods predicts diet quality in Canada. Appetite. 2017;108:512-20.

48. Machado PP, Steele EM, Levy RB, da Costa Louzada ML, Rangan A, Woods J, et al. Ultra-processed food consumption and obesity in the Australian adult population. Nutr Diabetes. 2020;10(1):1-11.

49. Cediel G, Reyes M, da Costa Louzada ML, Steele EM, Monteiro CA, Corvalán C, et al. Ultra-processed foods and added sugars in the Chilean diet (2010). Public Health Nutr. 2018;21(1):125-33.

50. Baker P, Machado P, Santos T, Sievert K, Backholer K, Hadjikakou $\mathrm{M}$, et al. Ultra-processed foods and the nutrition transition: global, regional and national trends, food systems transformations and political economy drivers. Obesity Reviews. 2020;21(12):e13126.

51. Moran AJ, Khandpur N, Polacsek M, Rimm EB. What factors influence ultra-processed food purchases and consumption in households with children? A comparison between participants 
and non-participants in the Supplemental Nutrition Assistance Program (SNAP). Appetite. 2019;134:1-8.

52. Franckle RL, Moran A, Hou T, Blue D, Greene J, Thorndike AN, et al. Transactions at a Northeastern supermarket chain: differences by Supplemental Nutrition Assistance Program use. Am J Prev Med. 2017;53(4):e131-8.

53. Baraldi LG, Steele EM, Canella DS, Monteiro CA. Consumption of ultra-processed foods and associated sociodemographic factors in the USA between 2007 and 2012: evidence from a nationally representative cross-sectional study. BMJ open. 2018;8(3).

54. Schnabel L, Kesse-Guyot E, Allès B, Touvier M, Srour B, Hercberg S, et al. Association between ultraprocessed food consumption and risk of mortality among middle-aged adults in France. JAMA Intern Med. 2019;179(4):490-8.

55. Elizabeth L, Machado P, Zinöcker M, Baker P, Lawrence M. Ultra-processed foods and health outcomes: a narrative review. Nutrients. 2020;12(7):1955.

56. Lane MM, Davis JA, Beattie S, Gómez-Donoso C, Loughman A, O'Neil A, et al. Ultraprocessed food and chronic noncommunicable diseases: a systematic review and meta-analysis of 43 observational studies. Obesity Reviews. 2021;22(3):e13146.

57. Pagliai G, Dinu M, Madarena M, Bonaccio M, Iacoviello L, Sofi F. Consumption of ultra-processed foods and health status: a systematic review and meta-analysis. Br J Nutr. 2021;125(3):308-18.

58. Konieczna J, Morey M, Abete I, Bes-Rastrollo M, Ruiz-Canela M, Vioque J, et al. Contribution of ultra-processed foods in visceral fat deposition and other adiposity indicators: prospective analysis nested in the PREDIMED-Plus trial. Clinical Nutrition. 2021.

59. Rauber F, Chang K, Vamos EP, da Costa Louzada ML, Monteiro $\mathrm{CA}$, Millett $\mathrm{C}$, et al. Ultra-processed food consumption and risk of obesity: a prospective cohort study of UK Biobank. Eur J Nutr. 2021;60(4):2169-80.

60. Canhada SL, Luft VC, Giatti L, Duncan BB, Chor D, Maria de Jesus $\mathrm{M}$, et al. Ultra-processed foods, incident overweight and obesity, and longitudinal changes in weight and waist circumference: the Brazilian Longitudinal Study of Adult Health (ELSABrasil). Public health nutrition. 2020;23(6):1076-86.

61. Fazzino TL, Dorling JL, Apolzan JW, Martin CK. Meal composition during an ad libitum buffet meal and longitudinal predictions of weight and percent body fat change: The role of hyperpalatable, energy dense, and ultra-processed foods. Appetite. 2021;167:105592 https://doi.org/10.1016/j.appet.2021.105592

62. Mendonça RdD, Lopes ACS, Pimenta AM, Gea A, MartinezGonzalez MA, Bes-Rastrollo M. Ultra-processed food consumption and the incidence of hypertension in a Mediterranean cohort: the Seguimiento Universidad de Navarra Project. American Journal of Hypertension. 2017;30(4):358-66.

63. Srour B, Fezeu LK, Kesse-Guyot E, Allès B, Méjean C, Andrianasolo RM, et al. Ultra-processed food intake and risk of cardiovascular disease: prospective cohort study (NutriNetSanté). bmj. 2019;365.

64. Srour B, Fezeu LK, Kesse-Guyot E, Allès B, Debras C, Druesne-Pecollo N, et al. Ultraprocessed food consumption and risk of type 2 diabetes among participants of the NutriNet-Santé prospective cohort. JAMA Intern Med. 2020;180(2):283-91.

65. Lavigne-Robichaud M, Moubarac J-C, Lantagne-Lopez S, Johnson-Down L, Batal M, Sidi EAL, et al. Diet quality indices in relation to metabolic syndrome in an Indigenous Cree (Eeyouch) population in northern Québec. Canada Public health nutrition. 2018;21(1):172-80.

66. Fiolet T, Srour B, Sellem L, Kesse-Guyot E, Allès B, Méjean $\mathrm{C}$, et al. Consumption of ultra-processed foods and cancer risk: results from NutriNet-Santé prospective cohort. bmj. 2018;360.
67. Kim H, Hu EA, Rebholz CM. Ultra-processed food intake and mortality in the United States: results from the Third National Health and Nutrition Examination Survey (NHANES III 19881994). Public Health Nutr. 2019;22(10): 1777.

68. DeSalvo KB, Olson R, Casavale KO. Dietary guidelines for Americans. JAMA. 2016;315(5):457-8.

69. Mullen A. Ultra-processed food and chronic disease. Nature Food. 2020;1(12):771-.

70. Askari M, Heshmati J, Shahinfar H, Tripathi N, Daneshzad E. Ultra-processed food and the risk of overweight and obesity: a systematic review and meta-analysis of observational studies. International Journal of Obesity. 2020:1-12.

71. Chen X, Zhang Z, Yang H, Qiu P, Wang H, Wang F, et al. Consumption of ultra-processed foods and health outcomes: a systematic review of epidemiological studies. Nutr J. 2020;19(1):1-10.

72. Askari M, Heshmati J, Shahinfar H, Tripathi N, Daneshzad E. Ultra-processed food and the risk of overweight and obesity: a systematic review and meta-analysis of observational studies. Int J Obes (Lond). 2020;44(10):2080-91.

73. Wang L, Steele EM, Du M, Pomeranz JL, O'Connor LE, Herrick KA, et al. Trends in consumption of ultraprocessed foods among US youths aged 2-19 years, 1999-2018. JAMA. 2021;326(6):519-30.

74. Filgueiras AR, de Almeida VBP, Nogueira PCK, Domene SMA, da Silva CE, Sesso R, et al. Exploring the consumption of ultraprocessed foods and its association with food addiction in overweight children. Appetite. 2019;135:137-45.

75. Chang K, Khandpur N, Neri D, Touvier M, Huybrechts I, Millett $\mathrm{C}$, et al. Association between childhood consumption of ultraprocessed food and adiposity trajectories in the Avon Longitudinal Study of Parents and Children Birth Cohort. JAMA pediatrics. 2021:e211573-e.

76. Vedovato GM, Vilela S, Severo M, Rodrigues S, Lopes C, Oliveira A. Ultra-processed food consumption, appetitive traits and BMI in children: a prospective study. Br J Nutr. 2021;125(12):1427-36.

77. Costa C, Rauber F, Leffa PS, Sangalli C, Campagnolo P, Vitolo MR. Ultra-processed food consumption and its effects on anthropometric and glucose profile: a longitudinal study during childhood. Nutr Metab Cardiovasc Dis. 2019;29(2):177-84.

78. Bleiweiss-Sande R, Sacheck JM, Chui K, Goldberg JP, Bailey C, Evans EW. Processed food consumption is associated with diet quality, but not weight status, in a sample of low-income and ethnically diverse elementary school children. Appetite. 2020;151:104696.

79. Oliveira T, Ribeiro I, Jurema-Santos G, Nobre I, Santos R, Rodrigues C, et al. Can the consumption of ultra-processed food be associated with anthropometric indicators of obesity and blood pressure in children 7 to 10 years old? Foods. 2020;9(11):1567.

80. Leffa PS, Hoffman DJ, Rauber F, Sangalli CN, Valmórbida JL, Vitolo MR. Longitudinal associations between ultraprocessed foods and blood lipids in childhood. Br J Nutr. 2020;124(3):341-8.

81. Rauber F, Campagnolo PDB, Hoffman DJ, Vitolo MR. Consumption of ultra-processed food products and its effects on children's lipid profiles: a longitudinal study. Nutr Metab Cardiovasc Dis. 2015;25(1):116-22.

82. Tavares LF, Fonseca SC, Rosa MLG, Yokoo EM. Relationship between ultra-processed foods and metabolic syndrome in adolescents from a Brazilian Family Doctor Program. Public Health Nutr. 2012;15(1):82-7.

83. Bawaked RA, Fernández-Barrés S, Navarrete-Muñoz EM, González-Palacios S, Guxens M, Irizar A, et al. Impact of lifestyle behaviors in early childhood on obesity and cardiometabolic risk 
in children: Results from the Spanish INMA birth cohort study. Pediatric obesity. 2020;15(3):e12590.

84. Movassagh EZ, Baxter-Jones AD, Kontulainen S, Whiting SJ, Vatanparast H. Tracking dietary patterns over 20 years from childhood through adolescence into young adulthood: The Saskatchewan Pediatric Bone Mineral Accrual Study. Nutrients. 2017;9(9):990.

85. Mikkilä V, Räsänen L, Raitakari O, Pietinen P, Viikari J. Consistent dietary patterns identified from childhood to adulthood: the cardiovascular risk in Young Finns Study. Br J Nutr. 2005;93(6):923-31.

86. Fardet A. Minimally processed foods are more satiating and less hyperglycemic than ultra-processed foods: a preliminary study with 98 ready-to-eat foods. Food Funct. 2016;7(5):2338-46.

87. Hall KD, Ayuketah A, Brychta R, Cai H, Cassimatis T, Chen KY, et al. Ultra-processed diets cause excess calorie intake and weight gain: an inpatient randomized controlled trial of ad libitum food intake. Cell metabolism. 2019;30(1):67-77. e3.

88. Juul F, Vaidean G, Parekh N. Ultra-processed foods and cardiovascular diseases: potential mechanisms of action. Advances in Nutrition. 2021.

89. Zinöcker MK, Lindseth IA. The Western diet-microbiomehost interaction and its role in metabolic disease. Nutrients. 2018;10(3):365.

90. Grundy MML, Lapsley K, Ellis PR. A review of the impact of processing on nutrient bioaccessibility and digestion of almonds. Int J Food Sci Technol. 2016;51(9):1937-46.

91. Moen B, Berget I, Rud I, Hole AS, Kjos NP, Sahlstrøm S. Extrusion of barley and oat influence the fecal microbiota and SCFA profile of growing pigs. Food Funct. 2016;7(2):1024-32.

92. Lane M, Howland G, West M, Hockey M, Marx W, Loughman A, et al. The effect of ultra-processed very low-energy diets on gut microbiota and metabolic outcomes in individuals with obesity: a systematic literature review. Obes Res Clin Pract. 2020;14(3):197-204.

93. Rancière F, Lyons JG, Loh VH, Botton J, Galloway T, Wang $\mathrm{T}$, et al. Bisphenol A and the risk of cardiometabolic disorders: a systematic review with meta-analysis of the epidemiological evidence. Environ Health. 2015;14(1):1-23.

94. Gibney MJ. Ultraprocessed foods and their application to nutrition policy. Nutr Today. 2020;55(1):16-21.

95. Crimarco A, Springfield S, Petlura C, Streaty T, Cunanan K, Lee J, et al. A randomized crossover trial on the effect of plantbased compared with animal-based meat on trimethylamine$\mathrm{N}$-oxide and cardiovascular disease risk factors in generally healthy adults: Study With Appetizing Plantfood-Meat Eating Alternative Trial (SWAP-MEAT). Am J Clin Nutr. 2020;112(5):1188-99.

96. Monteiro CA, Cannon G, Lawrence M, Costa Louzada Md, Pereira Machado P. Ultra-processed foods, diet quality, and health using the NOVA classification system. Rome, FAO. 2019.

97. Popkin BM, Barquera S, Corvalan C, Hofman KJ, Monteiro C, $\mathrm{Ng} \mathrm{SW}$, et al. Towards unified and impactful policies to reduce ultra-processed food consumption and promote healthier eating. The Lancet Diabetes \& Endocrinology. 2021.
98. Ng SW, Rivera JA, Popkin BM, Colchero MA. Did high sugarsweetened beverage purchasers respond differently to the excise tax on sugar-sweetened beverages in Mexico? Public Health Nutr. 2019;22(4):750-6.

99. Cobiac LJ, Tam K, Veerman L, Blakely T. Taxes and subsidies for improving diet and population health in Australia: a costeffectiveness modelling study. PLoS medicine. 2017;14(2):e1002232.

100. Peñalvo JL, Cudhea F, Micha R, Rehm CD, Afshin A, Whitsel $\mathrm{L}$, et al. The potential impact of food taxes and subsidies on cardiovascular disease and diabetes burden and disparities in the United States. BMC Med. 2017;15(1):1-13.

101. Mialon M, Crosbie E, Sacks G. Mapping of food industry strategies to influence public health policy, research and practice in South Africa. Int J Public Health. 2020;65(7):1027-36.

102. Machado PP, Steele EM, da Costa Louzada ML, Levy RB, Rangan A, Woods J, et al. Ultra-processed food consumption drives excessive free sugar intake among all age groups in Australia. Eur J Nutr. 2020;59(6):2783-92.

103. Harris RM, Rose AM, Soares-Wynter S, Unwin N. Ultra-processed food consumption in Barbados: evidence from a nationally representative, cross-sectional study. J Nutr Sci. 2021;10.

104. Setyowati D, Andarwulan N, Giriwono PE. Processed and ultraprocessed food consumption pattern in the Jakarta Individual Food Consumption Survey 2014. Asia Pac J Clin Nutr. 2018;27(4):840

105. Calixto Andrade G, Julia C, Deschamps V, Srour B, Hercberg S, Kesse-Guyot E, et al. Consumption of ultra-processed food and its association with sociodemographic characteristics and diet quality in a representative sample of French adults. Nutrients. 2021;13(2):682.

106. Costa CS, Del-Ponte B, Assunção MCF, Santos IS. Consumption of ultra-processed foods and body fat during childhood and adolescence: a systematic review. Public Health Nutr. 2018;21(1):148-59.

107. de Miranda RC, Rauber F, Levy RB. Impact of ultra-processed food consumption on metabolic health. Curr Opin Lipidol. 2021;32(1):24-37.

108. Moradi S, Entezari MH, Mohammadi H, Jayedi A, Lazaridi $\mathrm{A}-\mathrm{V}$, Kermani $\mathrm{MaH}$, et al. Ultra-processed food consumption and adult obesity risk: a systematic review and dose-response meta-analysis. Critical Reviews in Food Science and Nutrition. 2021:1-12.

109. Santos F, Dias M, Mintem G, Oliveira I, Gigante D. Food processing and cardiometabolic risk factors: a systematic review. Rev Saude Publica. 2020;54:70.

110. Silva Meneguelli T, Viana Hinkelmann J, Hermsdorff HHM, Zulet MÁ, Martínez JA, Bressan J. Food consumption by degree of processing and cardiometabolic risk: a systematic review. Int J Food Sci Nutr. 2020;71(6):678-92.

Publisher's Note Springer Nature remains neutral with regard to jurisdictional claims in published maps and institutional affiliations. 